\title{
Hydro-Metrological Drought Assessments along the Blue Nile River Basin in East Gojjam Zone
}

\author{
Walelgn Dilnesa \\ Lecture in DMU, IOT, and Hydraulic \&water Resources Engineering Ac/program
}

\begin{abstract}
The Upper Blue Nile basin is less-explored in drought studies as compared to other river basins in Ethiopia and a shortage of particular basin drought monitoring system. The area founds in along a Blue Nile basin faced a recurrent drought conditions in several years ago. The main objectives of this study to investigate droughts along a Blue Nile basin in the east Gojjam zone. To evaluate the drought duration, severity, occurrence and risks it was used different indices. The results shows a hydrological drought was occurring in a frequent condition in partial areas of Shebel Berenta, Goncha siso enese and Enarg enawuga woreda. Based on 12-month time-scale, the total number of drought events were identified in the area, using Reconnaissance drought index (RDI) during the period of analysis (1995-1996) and its values 100\% drought and its ranges were highly sever. Considering the drought events in the stream flow drought index (SDI) the values indicates drought severity was existed in the year 1984/1985 and 1989/1990. Inaddation standard precipitation index (SPI) also indicates a severe drought in $1984 / 1985,1990 / 1991$ and 1991/1992 and its values was -1.5. Generally the hydrological, metrological and agricultural drought where existed in the year (1984-2012) within the study area.
\end{abstract}

Keywords: RDI, Drought, SDI, SPI, NDVI

DOI: $10.7176 / \mathrm{CER} / 12-9-04$

Publication date:September $30^{\text {th }} 2020$

\section{BACKGROUND}

Drought is one of the most complex phenomena that can have a strong impact on agriculture, society, water resources and ecosystems. Drought affects many regions of the world and is globally one of the costliest climatic hazards. The event include low flow periods, but a continuous seasonal low-flow event does not necessarily constitute a drought River systems are most stressed in low flow periods and thus an understanding of drought conditions in time and space is fundamental to a wide range of water management problems (Hering et al., 2015).

Ethiopia, irrespective of its abundant potential of water resources, is facing drought at an increasing frequency throughout the past many decades. There have been notable droughts in Ethiopia thought out human history (Wolde-Georgis, 1997). Previous droughts and the frequency of rainfall deviation from the average suggest that drought occur every 3-5 and 6-8 years in northern Ethiopia and every 8-10 years for the whole country (Mohammed et al., 2018). About a century ago, the frequency of drought events in the country used to be once in every 10-15 years. However, recent records indicate increased incidences of drought events, with frequency of once in five years or even less. (Desalegn et al., 2006) reports that there is no regular cycle in the recurrence intervals of droughts in the country but an accumulation of a number of relatively dry years is likely to occur every 4-6 years.

Drought struck Ethiopia in 1888 , leading to the historic deadly famine of $1888 / 89$. About one-third of the population died because of famine, and $90 \%$ of the animals perished due to drought and drought related impacts (Wolde-Georgis, 1997). The 1957/58 drought and its related impacts led to famine in Tigray province and the 1972/73 famine caused by drought claimed 200,000 lives in Wollo province. Although the famine caused by drought of 1984-85 remains well known to the world community, less serious, nonetheless significant droughts, occurred in the years 1987, 1988, 1991-92, 1993-94, 1999, and 2002. Droughts entail loss of assets in the form of crops, livestock, and other productive capitals because of water shortages and related impacts. Droughts in Ethiopia had drastic impacts on agricultural output with total crop failure and massive livestock deaths recorded in many parts of the country. For instance, the 1984 drought in Wollo province led to a $61 \%$ and $94 \%$ decline in the yield of two important crops, teff and sorghum, respectively. According to (Keyantash and Dracup, 2004), droughts related to precipitation (meteorological), streamflow (hydrological), soil moisture (agricultural) or any combination of the three.

Drought is one of the recurring natural hazards in this area, in a survey conducted in the Upper Blue Nile Basin, reported that drought occurs every two years in the area (Gadisso, 2007). This study aims at establishing relationships between the meteorological, hydrological and agricultural drought indices in the study area as well as identifying the possible lag time among the three indices. The identified lag time utilized as a planning period for mitigating the impacts of hydrological drought that manifests because of rainfall shortages in the area. The overall objective of this study is to investigate drought characteristics and identify drought-prone areas along the Blue Nile river East Gojiam zone. Specifically to evaluate the severities of droughts in the study area, To examine the spatial and temporal variability of drought, To map drought probabilities and demarcate regions belonging to 
different class intervals of probabilities of drought and To develop composite drought indices with the combinations of meteorological, hydrological and agricultural drought. The drought was characterized into magnitude, duration, intensity, frequency, commencement and termination at the different time scales.

\section{METHODOLOGY}

\subsection{Locations of the Study Area}

The Upper Blue Nile (UBN) River originates at Lake Tana in Bahir Dar, flowing southeast through a series of cataracts. After about $150 \mathrm{~km}$, the river enters a deep canyon, and changes direction to the south. Many tributaries draining from many parts of the Ethiopian highlands join the main river along its course. Along this river basin in the southeast directions, it shows the recurrent drought events in the past few decades. The study area delineates based on the agro ecological zones and the area, particularly covers the agro ecological zones of between 5001500 kola to 1500-2300 dry woyna Dega (Hurni, 1998).

In the last few years, the area recurrently affected by the drought conditions and the nearest living society try to support the affected regions. This insufficient level of rainfall in long term it leads to food insecurity and poverty through the study area. Frequent droughts cause many poor farming families to live without food crops, leading to hunger and periodic famine (Hassen, 2008). This further prevents them from getting out of the desperate cycle of poverty. The overall impacts of drought in those watersheds also include loss in species biodiversity, migration changes, reduced air quality, and increased soil erosion. Therefore, the study of drought phenomena in the study area is mandatory.
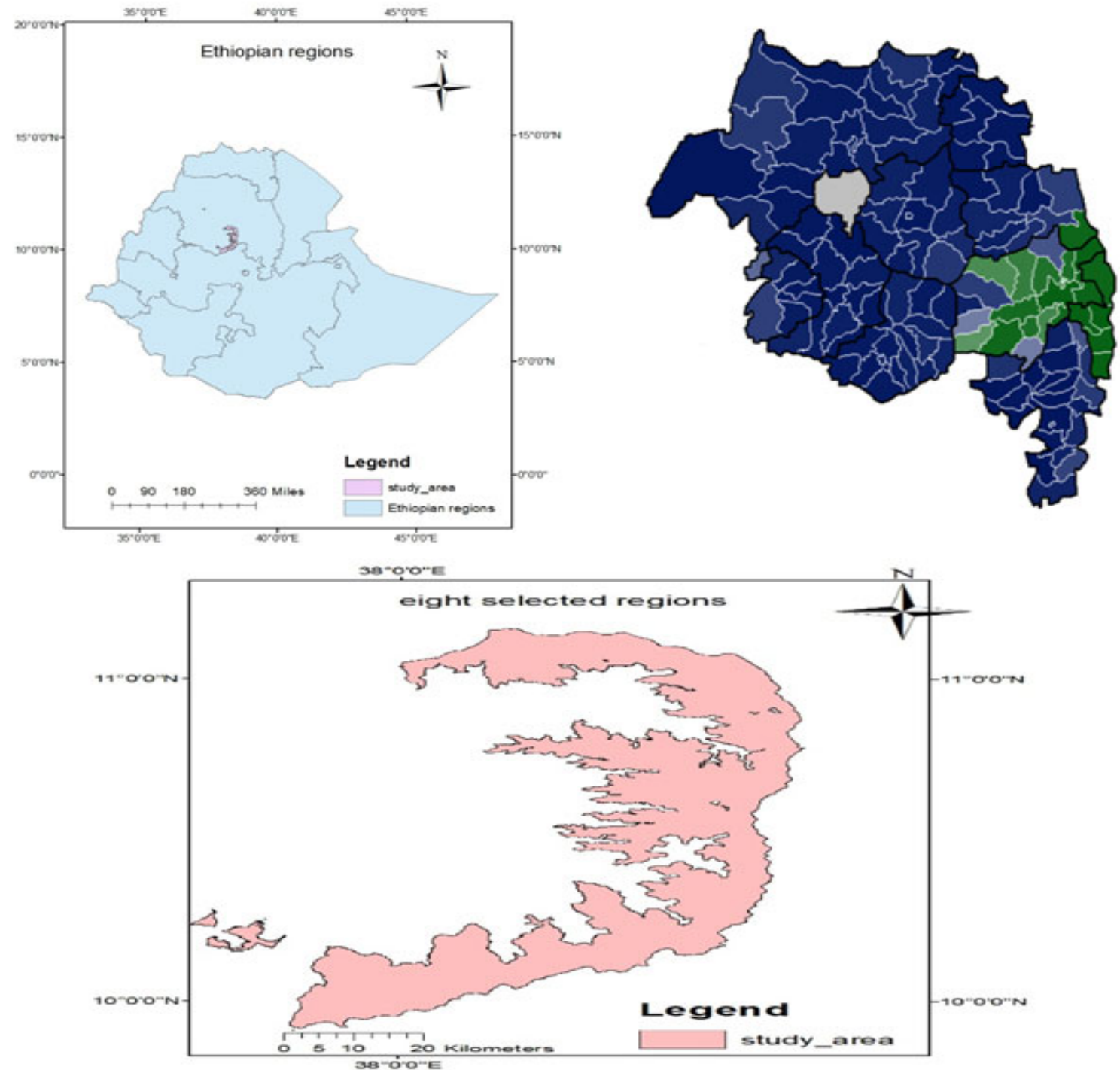

Figure 1 location of the study area

\subsection{Agro ecological zones}

The climate of Ethiopia shall classified in different ways, including the Traditional, Koppel's, Throw weights, 
rainfall regimes, and Agro climatic zone classification systems. The most common used classification systems are the traditional and the agro ecological zones. According to the traditional classification system, this mainly relies on altitude and temperature

There are five climatic zones namely classified depending up on the agro ecological zones: Wurch (cold climate at more than $3000 \mathrm{~m}$ altitude), Dega (temperate like climate-highlands with $2500-3000 \mathrm{~m}$ altitude), Woina Dega (warm at 1500-2500m altitude), Kola (hot and arid type, less than $1500 \mathrm{~m}$ in altitude), and Berha (hot and hyper-arid type) climate (NMSA, 2001). There is high spatial and temporal variation of rainfall in the study area. The main rainfall season, which accounts around $70-90 \%$ of the annual rainfall occur from June to September, while small rains also occur during December to March.

\subsection{Data collection and analysis}

During the data collection process the input data was obtained from different website sources and governmental institutions, it was the parts of metrological, hydrological and agricultural data. The metrological (maximum and minimum temperature) and hydrological (stream flow) data was obtained in free of charge from the national metrological agency of Ethiopian. And the stream flow data also obtained from the ministry of irrigation water resources and electricity of Ethiopia with a well recorded and tabulated manner for the inputs of DrinC software.

Next The data was organized and tabulated in Excel and then imported to DrinC (Drought Indices Calculator), 2015 software to calculate the standardized precipitation index (SPI), stream flow drought index (SDI), and Reconnaissance drought index (RDI) at different time scales for all the gauging stations using the data for the period 1984 to 2014 for the selected gauging stations under in the study area. As (Tigkas et al., 2015) presented the overall design and the implementation of the DrinC (Drought Indices Calculator) software along with the utilization of various approaches for drought analysis described in below.

\subsection{Drought Assessment Tool description}

DrinC (Drought Indices Calculator) aims at providing a user-friendly tool for the calculation of several drought indices. Key objective in its design was the widest possible applicability for several types of drought (meteorological, hydrological, agricultural) and different locations. It considered that drought studies are particularly essential in arid and semi-arid regions, where data availability is usually limited. Therefore, the main criteria for the selection of indices were:

a. To have relatively low data requirements, allowing the application of the software in many regions and

b. Their results to will be clearly interpret for direct and efficient operational use.

Based on these criteria, two recently developed and two most widely known indices were included in the DrinC: The Reconnaissance Drought Index (RDI), the Streamflow Drought Index (SDI), the Standardized Precipitation Index (SPI) and the Precipitation Deciles (PD). As can be easily understood, RDI, SPI and PD refer to the meteorological drought and use as main determinant the precipitation (and additionally the potential evapotranspiration for RDI only). Further, RDI can also be used for the agricultural drought analysis, as it can adequately describe the water balance, and it is particularly useful when reference periods related to development stages of the crop are selected (Tigkas et al., 2015).

On the other hand, SDI applies to hydrological drought and uses the streamflow as the key determinant. Apart from the originally proposed methods of calculation for each index, DrinC incorporates alternative methods that allow the comparison of the results among the indices. Further, this gives a key advantage to the user, since it provides the flexibility to select among various options for adjusting the outputs to his particular needs. Following, there is a short presentation and the key characteristics of the drought indices that can calculated by DrinC. For vegetation, index analysis will be used GIS and RS software to process the NDVI process. It was used Hydro climatic monthly data for each climate division Underwent correlation-based principal component analysis (PCA).

\subsection{Descriptions of Drought Indices \\ 2.5.1 Precipitation Deciles}

One of the simplest meteorological drought indices is the method of Deciles which was introduced by (Tsakiris et al., 2007). The precipitation totals for the preceding three months are ranked against climatologic records and if the sum falls within the lowest decile of the historical distribution of 3-month totals, then the region is considered to be under drought conditions (Heim Jr, 2002). 
Table 1: Precipitation declines description

\begin{tabular}{|l|l|}
\hline Decile class & Description \\
\hline Deciles $1-2$ lowest $20 \%$ & Much below normal \\
\hline Deciles $3-4$ next lowest $20 \%$ & Below normal \\
\hline Deciles $5-6$ middle $20 \%$ & Near normal \\
\hline Deciles $7-8$ next highest $20 \%$ & Above normal \\
\hline Deciles $9-10$ highest $20 \%$ & Much above normal \\
\hline
\end{tabular}

\subsubsection{Reconnaissance Drought Index (RDI)}

The Reconnaissance Drought Index (RDI) will be developed to approach the water deficit in a more accurate way, as a sort of balance between input and output in a water system (Kopsiaftis et al., 2017). It based both on cumulative precipitation (P) and potential evapotranspiration (PET), which are one measured (P) and one calculated (PET) determinant.

\subsubsection{Streamflow Drought Index (SDI)}

According to (Nalbantis, 2008), if a time series of monthly streamflow volumes $Q i, j$ is available, in which I denotes the hydrological year and $\mathrm{j}$ the month within that hydrological year $(j=1$ for October and $j=12$ for September), $V i, k$ can be obtained based on the equation:

$$
V_{i, k}=\sum_{j=1}^{3 k} Q_{i, j} i=1,2, \ldots \quad j=1,2, \ldots, 12 \quad k=1,2,3,4
$$

\subsubsection{Standardized Precipitation Index (SPI)}

For the SPI calculation, the long-term precipitation record for a desired period is fitted with a probability distribution, which is then transformed into a normal distribution so that the mean SPI for the location and desired period is zero. (Tsakiris and Vangelis, 2004) positive SPI values indicate greater than median precipitation, and negative values indicate less than median precipitation.

\subsection{Data Processing and Analysis}

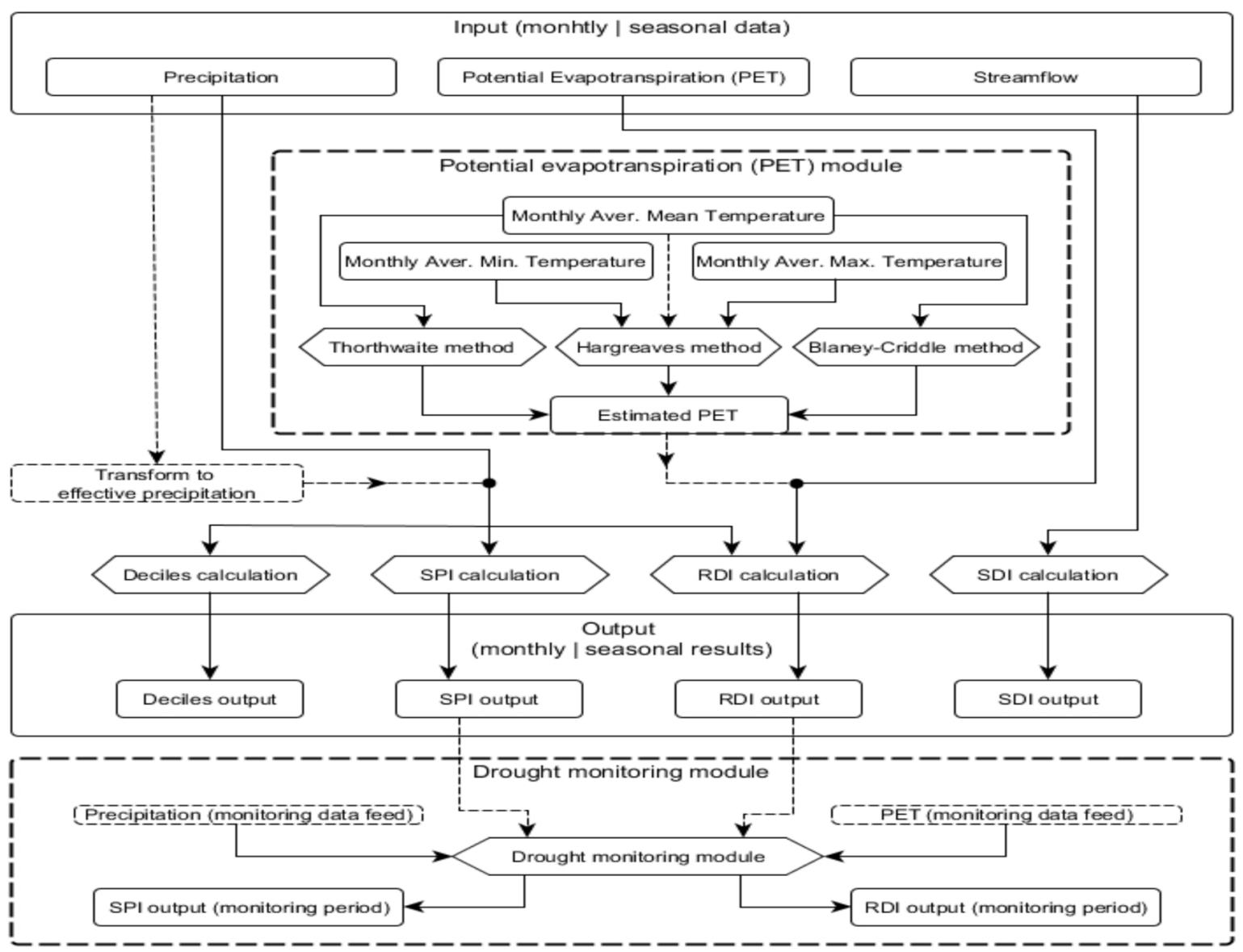

Figure 2:-workflow of drought analysis 


\section{RESULT AND DISCUSSION}

\subsection{Gauging Station of study area}

For drought analysis to use the gauging stations which recorded metrological, hydrological and agricultural data. Under the study area there are few synoptic or principal stations which records all metrological and hydrological data. The remaining gauging stations called secondary and thrasher gauging stations, which records mainly the precipitations, maximum and minimum temperatures with several year recording missing or gaps. During this study by taking this real conditions under in consideration it was selected the principal stations where located under in the study area. These gauging stations were, Motta, Shebel Berenta and Abay sheleko. Each stations and the corresponding detail analysis can show one by one in below.

\subsection{Yeduha gauging station}

This study refers to the drought conditions depends up on the agro ecological zones of the study area. The area consists on the dry woyna Dega and dry kola agro ecological zones which specially located on the lowest areas under in Blue Nile river basin around in east Gojjam and Wollo borders. Accordingly to assess this study it was used three gauging station which is located under in the study area. From those it were selected the Shebel Berenta gauging station. In 2002, Shebel Berenta was judged to be one of four chronically food insecure Woredas in this part of the Amhara Region, due to much of their farmland being "extremely depleted, deforested and eroded". So due to these it was selected these station gauging for one of the major analysis for drought study. In this station to evaluated the SPI, and SDI and RDI index analysis to value the potentials of drought in the study area. The values of each index shown below

\subsection{SPI (standard precipitation index)}

The output of SPI at different time scales and the drought characteristics at the mentioned gauging stations are presented. The analysis revealed five (5) characteristics of historical temporal drought/flood condition of the mentioned stations. The features of the dry/wet condition of the historical climate are: duration, frequency, intensity, severity and magnitude of the drought at different time scales of (SPI-3, SPI-6. SPI-9 and SPI-12) corresponding to 3, 6, 9 and 12 months respectively these refers to the short to long term seasonal conditions of drought in the study area with the corresponding Yeduha gauging stations. A 12-month SPI is a comparison of the precipitation for 12 consecutive months with the same 12 consecutive months during all the previous years of available data. The SPI at these time scales reflect long-term precipitation patterns. Because these time scales are the cumulative result of shorter periods that may be above or below normal, the longer SPIs tend toward zero unless a specific trend is taking place.

SPIs of these time scales are probably tied to stream flows, reservoir levels, and even groundwater levels at the longer time scales. In some locations of the country, the 12-month SPI is most closely related with the Palmer Index, and the two indices should reflect similar conditions.

Furthermore, the interim and termination of the climate events (drought) are indicated in Figure. As we have seen in figure 3 (a) The historical drought at the time scale of SPI-12 occurred in the following years, 1985, 1990, $1991,2002,2004$, and 2005, with the corresponding the severity extents of $-1.47,-1.47,-1.47,-0.13,-0.11$, and 0.23. The graphical representation shows the increase in drought pattern from 1985-1990, 1993-1995, 1998-2001, 2004, 2006 and 2008 the decrease in the drought phenomena 1991-1992, 1995-1997, 2003, 2007, 2010 and 2012 in figure $3(\mathrm{~b})$ in the study area of specially dry Kola regions of blue Nile basin.

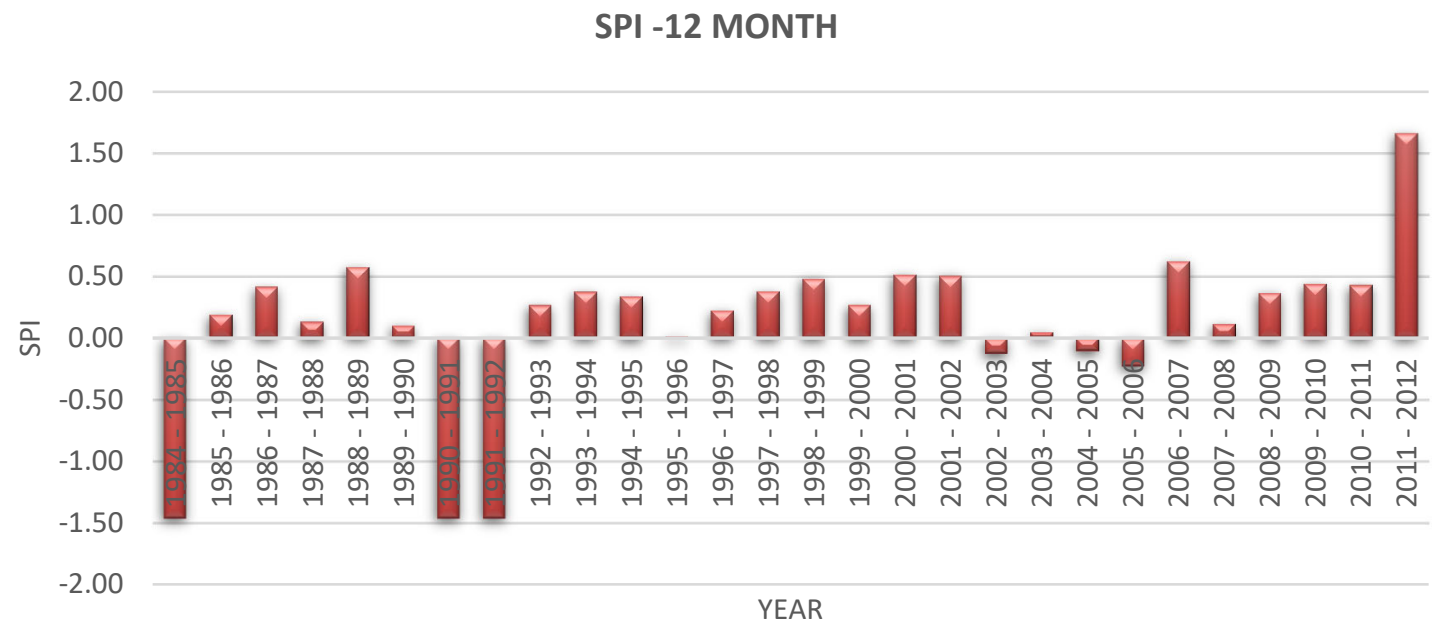

Figure 3: SPI values and drought events in the Yeduha gauging station from 1984-2012 under in the study area 
The 9-month SPI provides an indication of precipitation patterns over a medium time scale. Droughts usually take a season or more to develop. SPI values below -1.5 for these time scales are usually a good indication that fairly significant impacts are occurring in agriculture and may be showing up in other sectors as well. Some regions of the country may find that the pattern displayed by the map of the Palmer Index closely relates to the 9month SPI maps. For other areas, the Palmer Index is more closely related to the 12-month SPI. The Palmer Index maps are updated each week, although the patterns usually do not change significantly. The SPI maps are updated at the end of each month. For this gauging stations the 9 month drought was occurred in 1984/85, 1990/1992, $1994 / 1997,2001 / 2003,2005 / 2006,2007 / 2008$ and 2009/2012 in the corresponding year the maximum drought severity of -0.50 these mean that there was a short rainfall seasons in the study area and theses finally leads to the decrease in the surface water potential which called hydrological droughts.

The 6-month SPI compares the precipitation for that period with the same 6-month period over the historical record. The 6-month SPI indicates medium-term trends in precipitation and is still considered to be more sensitive to conditions at this scale than the Palmer Index. A 6-month SPI can be very effective showing the precipitation over distinct seasons. Information from a 6-month SPI may also begin to be associated with anomalous stream flows and reservoir levels. A 6 month drought was evaluated in the study area, in this month the drought event occurred in several months with a maximum drought severity factors of -1.50 in the year 1984/85, and 1991/1992.

The 3-month SPI provides a comparison of the precipitation over a specific 3-month period with the precipitation totals from the same 3-month period for all the years included in the historical record. In other words, a 3-month SPI at the end of February compares the December-January-February precipitation total in that particular year with the December-February precipitation totals of all the years. A 3-month SPI reflects short-and medium-term moisture conditions and provides a seasonal estimation of precipitation.

It is important to compare the 3-month SPI with longer time scales. A relatively normal 3-month period could occur in the middle of a longer-term drought that would only be visible at longer time scales. Looking at longer time scales would prevent a misinterpretation that any "drought" might be over.

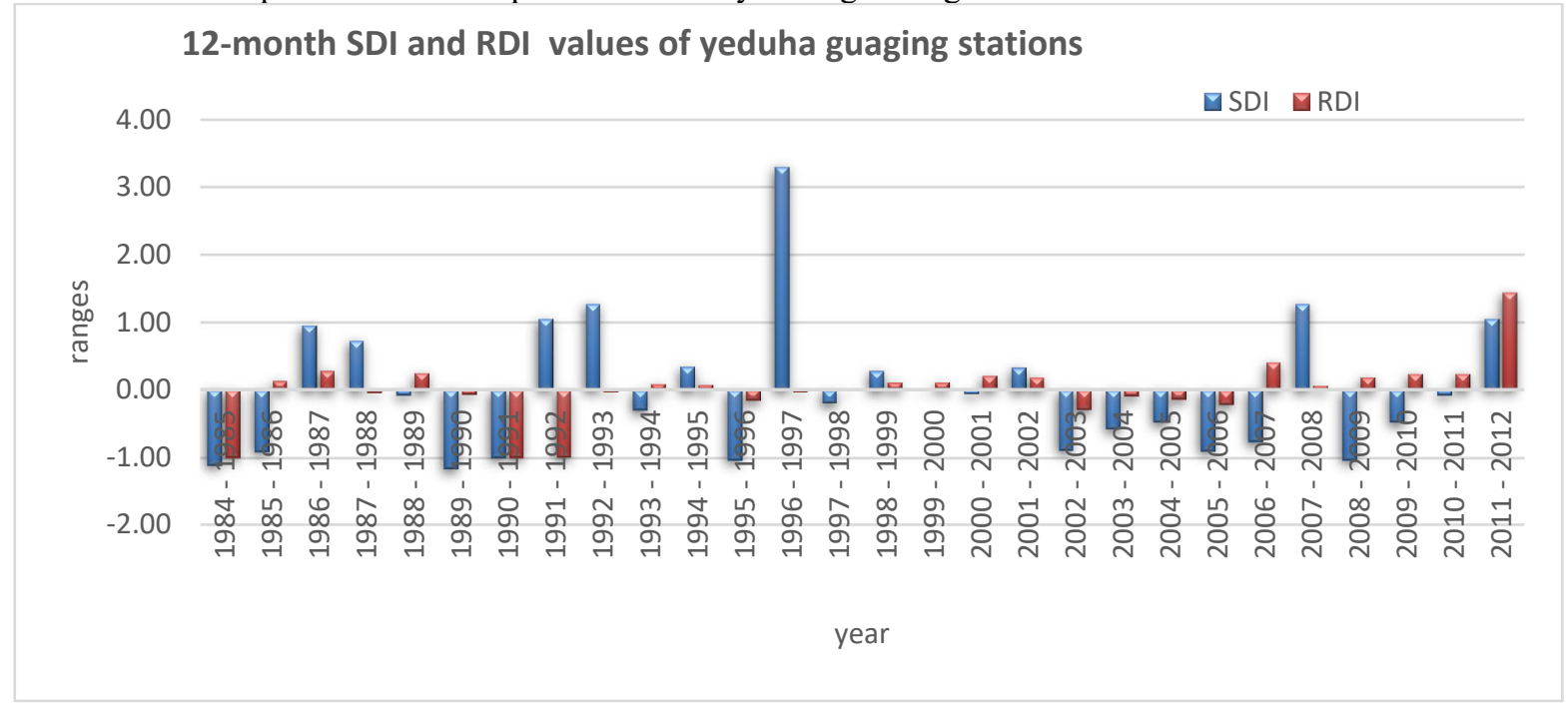

Figure 4 SDI and RDI values of Yeduha gauging stations

\subsection{Motta gauging station}

In this gauging stations under in the study area the three indices drought was evaluated in the years of 1984-2014 from the figure below the metrological drought occurred due to the shortage in precipitation in the year 1984/1985, with an extreme event and in the moderate range occurred in the year 1987/1988 and 2011/2014 in different months. In the low severity range in this gauging stations the events observed in the year 1985/1986.

The hydrological drought also revels in this gauging stations due to the decrees in levels of the stream flow, reservoir level, springs and swampy areas. This results shown by the below figures, the stream flow drought index states that there was an extreme stream flow drought happened in the year 2010/2014 and the moderate and low drought condition was observed in the year 1984/1985, 2010/2014 and 19990/2000 respectively 


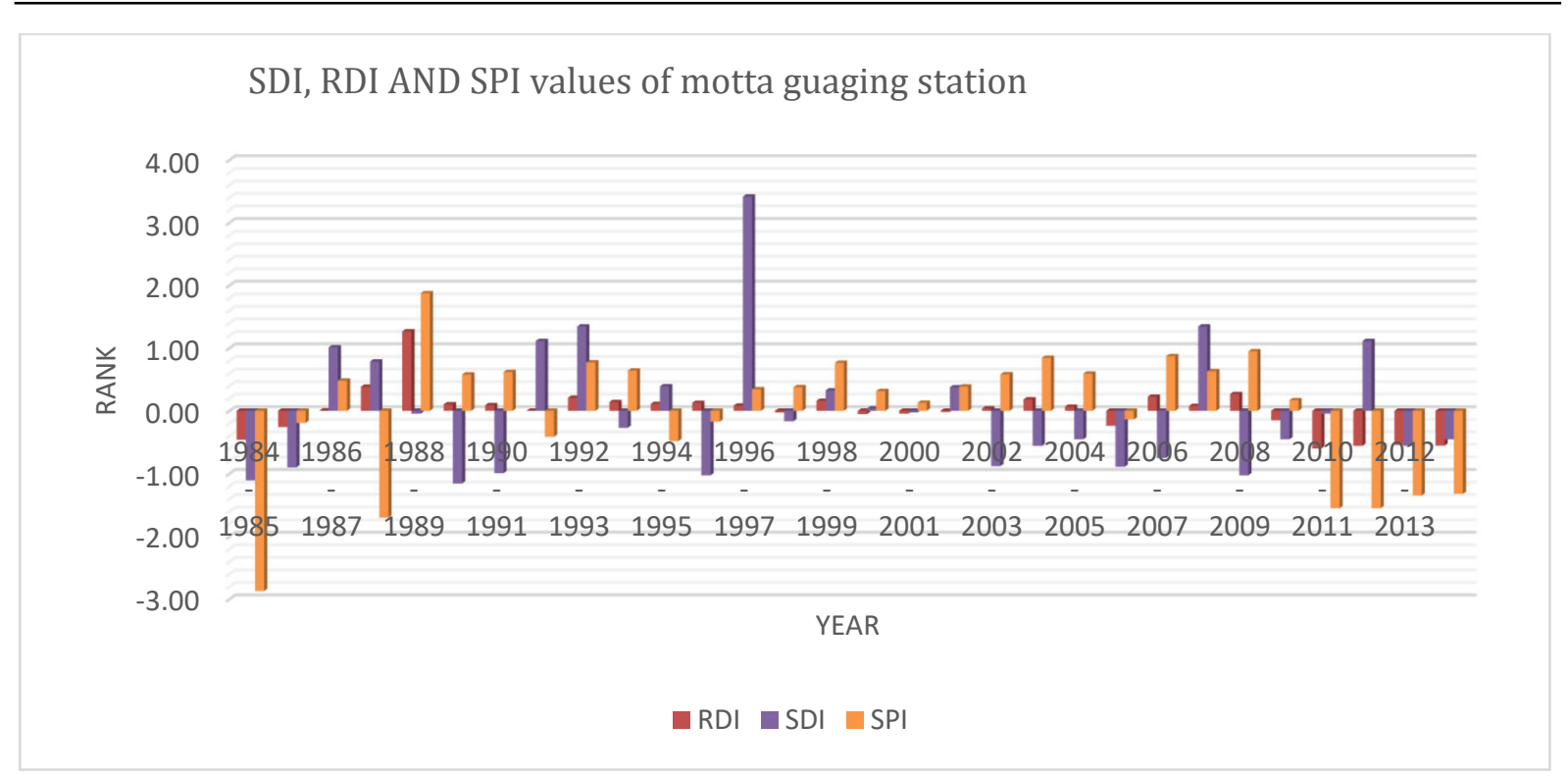

Figure 5 SPI, SDI and RDI values of the Motta gauging station in the study area

\subsection{Abay sheleko gauging stations}

In this gauging stations the extreme drought condition was happen in 1990/1991 and 1991/1992 with the severity values of -3.12 and -3.36. But the severe drought condition seen in 19984/19985, 2002/2003 and in the other years. The maximum stream flow drought index was in 1984/1985 with the severity values of -1.11 , and the RDI drought index was revels in 1990/1992 under in the study area in low land or kola regions of the parts of Abay river basin.

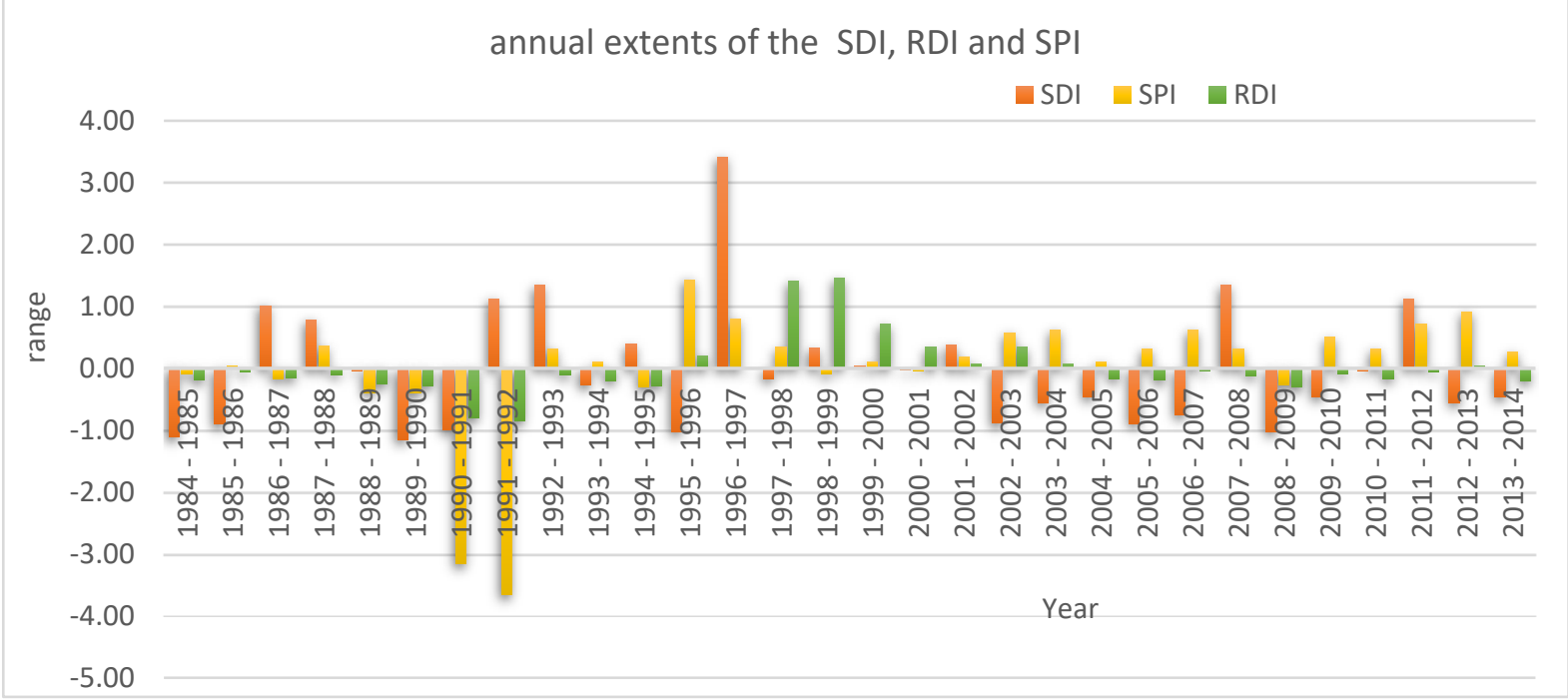

Figure 6 annual (12-month) of SPI, RDI and SDI values

\subsection{Drought Magnitude and Duration}

A drought event occurs whenever SPI, RDI and SDI values are continually negative and ends when the values become positive. Drought has a duration defined by its commencement and termination with the certain spatial and temporal references. The positive sum of the all the SPI, RDI and SDI values for all the months within a drought event is termed as drought magnitude. The intensity of drought event is defined as the ratio of event magnitude to its duration. The historical and consecutive 30 years drought characteristics like drought duration, magnitude and intensity are presented in the Table-3 for the 3-giguging station which represents the whole study area.

The drought conditions in the year 1984 was the longest dry seasons which covers 12 month with its magnitude of 8.3 and its intensity was 0.725 in the Motta gauging stations. Whereas the Abay sheleko gauging station experienced the longest drought seasons in 1986 with his 11 months in the magnitude of 0.26 and its corresponding intensity was 0.02 . In the year 1988 it was the drought magnitude 12 months indicates that the area covers the longest drought seasons but its severity was minimum. Yeduha stations also observed the higher drought 
seasons in the year 1984and 1990 with the maximum magnitude levels of 11 months. From the 3 gauging stations the most severe drought occurred in the study area was in the year 2006 with the intensity of 5.23 in the Yeduha gauging stations, 10.12 in Motta gauging stations and 2.44 in the Abay sheleko gauging stations. However, in terms of drought intensity the maximum intensity cannot imply that longer may not be the most severe. Dry spells impact greatly on agriculture (crop production) than

More intense drought occurrences.

This finding is in agreement with (Simelton et al., 2009) study of drought who says that small drought can have bigger impacts than bigger drought. The main thing that dry season's spills an erratic conditions and its can happen in several times at the critical periods of the rainy seasons of the study area which leads to decrease in soil water holding capacity of the surrounding area and the chance of surface water percolating to the ground surface. This phenomena finally leads to the probably of occurrence agricultural drought to severe plant water stress and exposures to the total crop failures.

Table 2 SPI values of the 3-guaging stations in the study area

\begin{tabular}{|l|l|l|l|l|}
\hline \multicolumn{2}{|l|}{ Yeduha gauging stations } & \multicolumn{3}{|l|}{ SPI Drought index } \\
\hline year & month & duration & magnitude & intensity \\
\hline 1984 & Except 3 & 11 & 0.09 & 0.008 \\
\hline 1985 & $5,9,11$ & 3 & 3.59 & 1.2 \\
\hline 1986 & $2,4,8,10,11$ & 5 & 7.96 & 1.6 \\
\hline 1987 & $2,4,5,10,12$ & 5 & 3.84 & 0.768 \\
\hline 1988 & $2,6,7,8,9$ & 5 & 6.53 & 1.3 \\
\hline 1989 & $2,4,5,8,910,12$ & 7 & 2.76 & 0.4 \\
\hline 1990 & excepyt,3 & 11 & 0.09 & 0.008 \\
\hline 1991 & except, 3,4 & 10 & 0.34 & 0.034 \\
\hline 1992 & $4,5,6,7,8,9,10$ & 7 & 5.40 & 0.77 \\
\hline 1993 & 2,11 & 2 & 6.01 & 3.005 \\
\hline 1994 & $1,4,5,7,8$ & 5 & 2.45 & 0.5 \\
\hline 1995 & $1,2,4,6,9,10,12$ & 8 & 3.94 & 0.5 \\
\hline 1996 & $1,5,9,10,11,12$ & 6 & 6.43 & 1.07 \\
\hline 1997 & $4,5,10,11,12$ & 6 & 7.85 & 1.30 \\
\hline 1998 & $4,7,10$ & 3 & 5.03 & 1.67 \\
\hline 1999 & $5,6,7,8,9,12$ & 6 & 4.77 & 0.8 \\
\hline 2000 & $4,5,6,9$ & 4 & 6.52 & 1.63 \\
\hline 2001 & $1,4,7,12$ & 4 & 4.87 & 1.21 \\
\hline 2002 & $1,2,6,7,8,9,11,12$ & 8 & 4.62 & 0.57 \\
\hline 2003 & $1,4,7,8,9,10$ & 6 & 5.33 & 0.89 \\
\hline 2004 & $2,8,10,11,12$ & 6 & 2.68 & 0.45 \\
\hline 2005 & $1,2,5,6,8,11,12$ & 7 & 2.00 & 0.28 \\
\hline 2006 & 5 & 1 & 5.23 & 5.23 \\
\hline 2007 & $1,2,6,7,10$ & 5 & 6.42 & 1.28 \\
\hline 2008 & $4,5,6,7,9$ & 5 & 6.42 & 1.28 \\
\hline 2009 & $1,6,7,9,12$ & 5 & 4.34 & 0.86 \\
\hline 2010 & $1,4,5,11$ & 4 & 5.20 & 1.32 \\
\hline 2011 & $1,4,5$ & 3 & 13.30 & 4.43 \\
\hline 2012 & 1,4 & 2 & 4.22 & 2.11 \\
\hline & & & & \\
\hline
\end{tabular}




\begin{tabular}{|c|c|c|c|c|}
\hline \multicolumn{2}{|c|}{ Motta gauging stations } & \multicolumn{3}{|c|}{ SPI Drought index } \\
\hline year & month & Duration & magnitude & intensity \\
\hline 1984 & All month & 12 & 8.7 & 0.725 \\
\hline 1985 & $1,2,7,8,9,10,11$ & 7 & 3.06 & 0.43 \\
\hline 1986 & $8,9,10,11$ & 4 & 4.71 & 1.17 \\
\hline 1987 & $2,3,4,5,6,7,8,10.11$ & 9 & 4.55 & 0.50 \\
\hline 1988 & 8 & 1 & 19.12 & 19.12 \\
\hline 1989 & $8,10,11$ & 3 & 4.97 & 1.65 \\
\hline 1990 & 3 & 1 & 6.60 & 6.60 \\
\hline 1991 & $3,4,5,6,11,12$ & 6 & 2.81 & 0.46 \\
\hline 1992 & 11 & 1 & 5.79 & 5.79 \\
\hline 1993 & 12 & 1 & 4.49 & 4.49 \\
\hline 1994 & $1,2,3,4,5,12$ & 6 & 2.20 & 0.36 \\
\hline 1995 & $9,10,11,12$ & 4 & 3.76 & 0.94 \\
\hline 1996 & $1,10,11,12$ & 4 & 4.09 & 1.02 \\
\hline 1997 & $1,2,12$ & 3 & 4.09 & 1.36 \\
\hline 1998 & 11,12 & 2 & 6.06 & 3.03 \\
\hline 1999 & 11,12 & 2 & 2.68 & 1.34 \\
\hline 2000 & $1,11,12$ & 3 & 2.19 & 0.73 \\
\hline 2001 & $1,2,11,12$ & 4 & 3.20 & 0.8 \\
\hline 2002 & 11,12 & 2 & 4.08 & 2.04 \\
\hline 2003 & 11 & 1 & 5.97 & 5.97 \\
\hline 2004 & 9,10 & 2 & 5.34 & 2.67 \\
\hline 2005 & $9,10,11,12$ & 4 & 4.11 & 1.0275 \\
\hline 2006 & none & 0 & 7.11 & 0 \\
\hline 2007 & $10,11,12$ & 3 & 4.78 & 1.6 \\
\hline 2008 & 10 & 1 & 10.12 & 10.12 \\
\hline 2009 & $4,6,10,11,12$ & 5 & 5.58 & 1.1 \\
\hline 2010 & $1,2,3,4,5,6,7,8,12$ & 9 & 1.77 & 0.2 \\
\hline 2011 & $1,2,3,4,5,6,7,8,9,12$ & 10 & 1.77 & 0.18 \\
\hline 2012 & $1,2,3,4,5,6,7,8,9,12$ & 10 & 0.81 & 0.081 \\
\hline 2013 & $2,3,4,5,6,7,8,9,12$ & 9 & 3.03 & 0.33 \\
\hline 2014 & $3,4,5.6$ & 4 & 2.01 & 0.50 \\
\hline
\end{tabular}




\begin{tabular}{|c|c|c|c|c|}
\hline \multicolumn{2}{|c|}{ Abay sheleko stations } & \multicolumn{3}{|c|}{ SPI Drought index } \\
\hline Year & Month & Duration & Magnitude & intensity \\
\hline 1984 & $1,2,3,4,5,6,11,12$ & 8 & 0.62 & 0.0775 \\
\hline 1985 & $8,10,11$ & 3 & 0.62 & 0.2 \\
\hline 1986 & Except month 12 & 11 & 0.26 & 0.02 \\
\hline 1987 & 12 & 1 & 2.8 & 2.8 \\
\hline 1988 & All month & 12 & 12 & 1 \\
\hline 1989 & All month & 12 & 12 & 1 \\
\hline 1990 & All month & 12 & 12 & 1 \\
\hline 1991 & All month & 12 & 12 & 1 \\
\hline 1992 & 10,11 & 2 & 3.02 & 1.51 \\
\hline 1993 & 11,12 & 2 & 1.25 & 0.625 \\
\hline 1994 & $1,2,3,4,5,6,7$ & 7 & 3.39 & 0.484 \\
\hline 1995 & none & 0 & 17.50 & 0 \\
\hline 1996 & 11 & 1 & 6.85 & 6.85 \\
\hline 1997 & 9,10 & 2 & 2 & 1 \\
\hline 1998 & All month & 12 & 0 & 0 \\
\hline 1999 & none & 0 & 3.28 & 0 \\
\hline 2000 & All month & 12 & 0.12 & 0.01 \\
\hline 2001 & $1,2,3,4,5,6,7,8,9,10$ & 10 & 0.26 & 0.026 \\
\hline 2002 & $2,3,4,5,6,7,8,9$ & 8 & 7.73 & 0.966 \\
\hline 2002 & none & 0 & 8.79 & 0 \\
\hline 2003 & 12 & 1 & 1.32 & 1.32 \\
\hline 2004 & $2,3,4,5,6$ & 5 & 5.31 & 1.062 \\
\hline 2005 & none & 0 & 7.5 & 0 \\
\hline 2006 & none & 0 & 2.28 & 0 \\
\hline 2007 & $9,10,11,12$ & 4 & 7.61 & 1.9025 \\
\hline 2008 & $1,2,3,4,5,6,7,8,11$ & 9 & 7.6 & 0.844 \\
\hline 2009 & none & 0 & 2.80 & 0 \\
\hline 2010 & $3,4,5,6,7$ & 5 & 12.20 & 2.44 \\
\hline 2011 & none & 0 & 9.08 & 0 \\
\hline 2012 & none & 0 & 0 & 0 \\
\hline 2013 & 1 & 1 & 2.03 & 2.03 \\
\hline 2014 & 2,3 & 1 & 2.00 & 2.00 \\
\hline
\end{tabular}

Note month start with October.....

\subsection{Drought Frequency Distribution (Probability of Occurrence)}

The main goal of showing drought frequency and probability occurrence to identify the drought severity at different levels and their probability of occurrence in different category. This revelation implies that the extreme climatic events are rare thought drought frequency in general on the ascendancy. Respectively presented the drought frequencies of various categories, revealed by SPI over the watershed relating to the total number of drought events that occurred during the period under study. The figures 8 shown in below indicated the probability of occurrence $(\%)$ of drought events at different time scale. It is clearly observed that for all the different time scales, the near normal droughts occurred most frequently and it covers $86 \%$, the severe drought events occurred least frequently and the moderate drought conditions was observed in $11 \%$. In the Yeduha gauging station extreme drought condition cannot occurred.

In the Motta gauging station under in the study area the extreme drought condition occurred in 12 month SPI with in the total percentage of 3 and also the severe and moderate drought was occurred under in the study years of 1984-2014. Thus soil moisture for agricultural production could be negatively impacted as well as the underground water availability. The aim of the drought frequency analysis is to identify the drought of different severity levels and their probability of occurrence. This revelation implies that the extreme climatic events are rare though drought frequency in general is on the ascendancy. similar study in awash river basin Ethiopia, reported that a 12 month extreme drought conditions was observed since 1984/85 (Edossa et al., 2010). In three gauging stations generally it occur the deficiency in precipitation, stream flow, reservoir level and the ground water aquifer recharge. Most commonly the precipitation amount falls in the study area, these conditions mainly contributes to the occurrence of stream flow drought index in combined manner. 
extremly wet

very wet

moderatly wet

near normal

moderatly dry

severly dry

axtremly dry

\section{2-month SPI motta station}

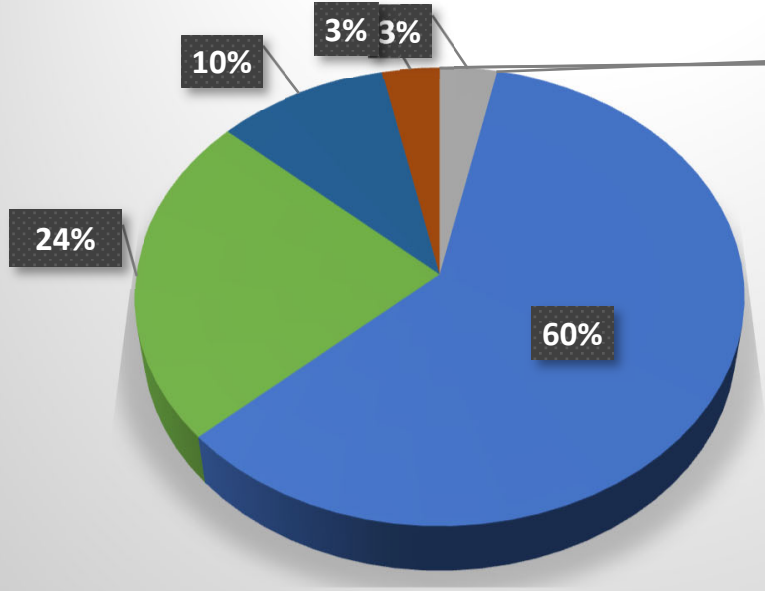

\section{$0 \%-0 \% \quad 0 \%$}

extremly wet

very wet

moderatly wet

near normal

moderatly dry

severly dry

extremly dry

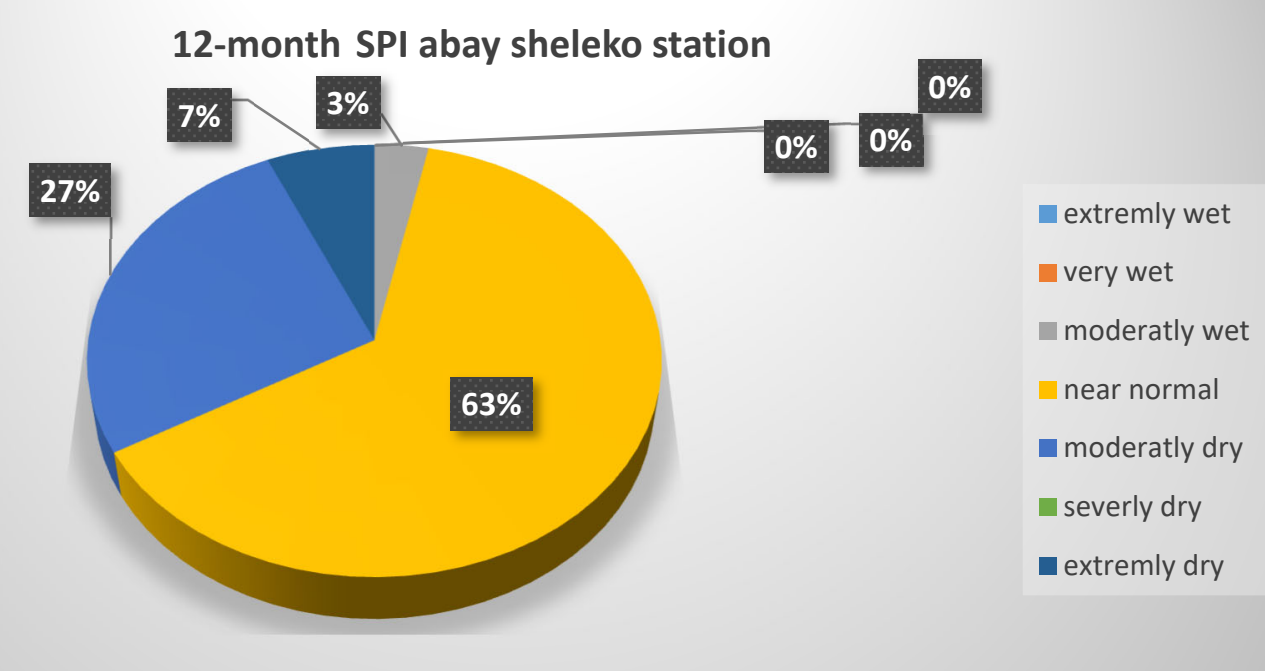

Figure 7 the frequency and probability occurrences of the 3 gauging station (1984-2014)

\subsection{Conclusion}

The tendency towards dryness is higher in magnitude and severity at the Motta gauging stations than the others. 
The probable explanation could be the difference in the agro ecological zones and therefore the geomorphology, it is concluded that, the increasing rainfall variability and rising temperature attributable to anthropogenic activities may not be the only cause for drought events intensity and frequency over the study area. It is recommended that a further study be conducted to ascertain the roles played by land use/land cover or other anthropogenic factors which contributes to drought events in the basin regions. Inaddation suggested that spatial analysis of drought be conducted in the future to know the spatial extent of drought phenomena the whole parts as data become available all gauging stations under the study area.

\subsection{Recommendation}

Drought indices and early warning systems must be implemented with end users in mind. To accomplish this goal, a multidisciplinary approach incorporating user involvement is necessary. The National Meteorological and Hydrological Services (NMHSs) around the world are encouraged to use the SPI to characterize meteorological droughts and provide this information on their Web sites, in addition to the indices currently in use. A comprehensive study of consensus drought indicators needed for potential global application. A simple, systematic analysis of drought impacts in different sectors should be initiated in all affected countries to provide useful decision-making information for policymakers.

\section{ACKNOWLEDGEMENTS}

I am greatly acknowledge for national metrological agency land ministry of water resources irrigation and electricity staff members to offer the metrological and hydrological data in free of charge.

\section{REFERENCE}

DESALEGN, C. E., BABEL, M. S., GUPTA, A. D., SELESHI, B. A. \& MERREY, D. 2006. Farmers' perception of water management under drought conditions in the upper Awash Basin, Ethiopia. International Journal of Water Resources Development, 22, 589-602.

EDOSSA, D. C., BABEL, M. S. \& GUPTA, A. D. 2010. Drought analysis in the Awash river basin, Ethiopia. Water resources management, 24, 1441-1460.

GADISSO, B. E. Drought assessment for the Nile Basin using Meteosat second generation data with special emphasis on the upper Blue Nile Region. 2007. ITC.

HASSEN, A. 2008. Vulnerability to drought risk and famine: Local responses and external interventions among the Afar of Ethiopia, a study on the Aghini Pastoral Community.

HEIM JR, R. R. 2002. A review of twentieth-century drought indices used in the United States. Bulletin of the American Meteorological Society, 83, 1149-1165.

HERING, D., CARVAlHO, L., ARGILliER, C., BEKlioglu, M., BORJA, A., CARDOSO, A. C., DUEL, H., FERREIRA, T., GLOBEVNIK, L. \& HANGANU, J. 2015. Managing aquatic ecosystems and water resources under multiple stress-An introduction to the MARS project. Science of the total environment, 503, 10-21.

HURNI, H. 1998. Agroecological belts of Ethiopia. Explanatory notes on three maps at a scale of, 1.

KEYANTASH, J. A. \& DRACUP, J. A. 2004. An aggregate drought index: Assessing drought severity based on fluctuations in the hydrologic cycle and surface water storage. Water Resources Research, 40.

KOPSIAFTIS, G., TIGKAS, D., CHRISTELIS, V. \& VANGELIS, H. 2017. Assessment of drought impacts on semi-arid coastal aquifers of the Mediterranean. Journal of Arid Environments, 137, 7-15.

MOHAMMED, Y., YIMER, F., TADESSE, M. \& TESFAYE, K. 2018. Meteorological drought assessment in north east highlands of Ethiopia. International Journal of Climate Change Strategies and Management, 10, 142-160.

NALBANTIS, I. 2008. Evaluation of a hydrological drought index. European Water, 23, 67-77.

SIMELTON, E., FRASER, E. D., TERMANSEN, M., FORSTER, P. M. \& DOUGILL, A. J. 2009. Typologies of crop-drought vulnerability: an empirical analysis of the socio-economic factors that influence the sensitivity and resilience to drought of three major food crops in China (1961-2001). Environmental Science \& Policy, 12, 438-452.

TIGKAS, D., VANGELIS, H. \& TSAKIRIS, G. 2015. DrinC: a software for drought analysis based on drought indices. Earth Science Informatics, 8, 697-709.

TSAKIRIS, G., LOUKAS, A., PANGALOU, D., VANGELIS, H., TIGKAS, D., ROSSI, G. \& CANCELLIERE, A. 2007. Drought characterization. Drought management guidelines technical annex, 85-102.

TSAKIRIS, G. \& VANGELIS, H. 2004. Towards a drought watch system based on spatial SPI. Water resources management, 18, 1-12.

WOLDE-GEORGIS, T. 1997. El Nino and drought early warning in Ethiopia. 